\title{
Review
}

Neuro epidemiology

\section{Non-Motor Symptoms Assessed by Non-Motor Symptoms Questionnaire and Non-Motor Symptoms Scale in Parkinson's Disease in Selected Asian Populations}

\author{
Anna Sauerbier ${ }^{a, b}$ Onanong Jitkritsadakule Nataliya Titova ${ }^{f} \quad$ Lisa Klingelhoeferg $^{g}$ \\ Yoshio Tsuboi $^{\text {h }}$ Harry Carr $^{b}$ Hrishikesh Kumar ${ }^{i}$ Rebecca Banerjee ${ }^{i}$ Roberto Erro ${ }^{j}$ \\ Roongroj Bhidayasirie Anette Schrag ${ }^{d}$ Panagiotis Zis ${ }^{c}$ Shen-Yang Lim ${ }^{k}$ \\ J.Y. Al-Hashel ${ }^{\text {l, } m}$ Walaa A. Kamel ${ }^{\text {, } n}$ Pablo Martinez-Martin ${ }^{\circ}$ K. Ray Chaudhuria, b \\ ${ }^{a}$ Neurology, King's College Hospital, and ' Institute of Psychiatry, Psychology and Neuroscience, King's College, London, \\ ${ }^{c}$ Academic Department of Neurosciences, Sheffield Teaching Hospitals NHS Foundation Trust, Sheffield, and d UCL Institute \\ of Neurology, University College London, London, UK; ${ }^{\mathrm{e}}$ Neurology, Chulalongkorn University Hospital, Bangkok, Thailand; \\ ${ }^{f}$ Federal State Budgetary Educational Institution of Higher Education "N.I. Pirogov Russian National Research Medical \\ University" of the Ministry of Healthcare of the Russian Federation, Moscow, Russia; ${ }^{9}$ Department of Neurology, Technical \\ University Dresden, Dresden, Germany; ${ }^{h}$ Fifth Department of Internal Medicine, Fukuoka University, Fukuoka, Japan; \\ iInstitute of Neurosciences, Kolkata, India; 'ंCenter for Neurodegenerative diseases (CEMAND), Department of Medicine, \\ Neuroscience Section, University of Salerno, Salerno, Italy; ${ }^{\mathrm{k}}$ Division of Neurology, University of Malaya, Kuala Lumpur, \\ Malaysia; 'Neurology Department, Ibn Sina Hospital, and mHealth Sciences Centre, Kuwait University, Kuwait, Kuwait; \\ ${ }^{n}$ Neurology, Beni-Suef University, Beni-Suef, Egypt; ${ }^{\circ}$ National Center of Epidemiology and CIBERNED, Carlos III Institute of \\ Health, Madrid, Spain
}

\section{Keywords}

Non-motor symptoms · Parkinson · Asia · Ethnicity

\begin{abstract}
Background: Ethnic variations have been described in medical conditions, such as hypertension, diabetes, and multiple sclerosis. Whether ethnicity plays a role in Parkinson's disease (PD), particularly with regard to non-motor symptoms (NMS), remains unclear. Existing literature is diverse, controversial, and inadequately documented. This review aims to analyse and report the currently available literature on NMS, specifically in Asian PD patients. Summary: We conducted a literature review using PubMed, searching for articles and currently available publications that reference and assess NMS in PD
\end{abstract}

patients living in Asia using the validated NMS Questionnaire (NMS Quest) and NMS Scale (NMSS). In total, 24 articles were included: 12 using the NMS Quest and 12 using the NMSS. Symptoms of constipation, memory impairment, and nocturia were the most frequently self-reported symptoms (NMS Quest) in selected Asian populations, while symptoms within the domains sleep/fatigue, attention/memory, and mood/ apathy were most prevalent when applying the health-professional completed NMSS. Key Messages: NMS are generally prevalent and highly burdensome within selected Asian PD populations living in countries included in this review. Our review suggests that NMS-driven phenotypic heterogeneity is present in Asian patients, and compared to Western PD populations there might be variations in assessed NMS.

(c) 2017 S. Karger AG, Basel

\section{KARGER}

(c) 2017 S. Karger AG, Basel 


\section{Introduction}

Parkinson's disease (PD) affects people from both genders, across a wide age range and across all racial groups [1]. Patterns of motor response to levodopa may vary between ethnicity, as reported in one study in resident immigrant Asian and Black African-Caribbean populations from the UK [2]. The assessment and interpretation of the literature regarding multiethnic $\mathrm{PD}$ is challenging due to differences in applied study designs with varying sample sizes, definitions of ethnicity, and lack of use of validated measures [3, 97].

$\mathrm{PD}$ is a combined motor and non-motor syndrome, a fact recognised by James Parkinson himself $[4,5]$. While motor symptoms are certainly burdensome, the wide range of non-motor symptoms (NMS) have emerged as a key determinant of quality of life (QoL) in PD patients, both untreated and treated $[6,7]$. Whether NMS vary between ethnic groups is currently unknown. This question is certainly relevant as many NMS could be influenced by numerous factors including socio-demographic factors, cultural backgrounds, as well as pharmacogenomics $[8,9$, 97]. A recent review on NMS in Chinese patients outlined that whilst NMS appear to be as common in China as in the Western world, there appears to be some inter-ethnic variations in their clinical presentations [3]. Furthermore, previous international studies have suggested differences in the presentation and range of motor symptoms and NMS related to ethnicity [2, 10-14].

Some studies in Asia used validated questionnaires and scales to assess the prevalence of NMS in a holistic manner, hence permitting the comparison of their results [14]. In this literature review, we aim to summarise the available studies addressing NMS in native Asian PD patients by applying the NMS Questionnaire (NMS Quest) and NMS Scale (NMSS). Furthermore, where possible, we discuss the potential underlying causes for ethnic variations in NMS.

\section{Methods}

In accordance with PRISMA guidelines (2009), a literature search was carried out on March 8, 2017 using the advanced search builder for all fields on the PubMed database, covering all articles published before that date. The search strategy is summarised in Figure 1 [15]. First, we excluded all duplicates and then screened the abstracts of the remaining articles against specific inclusion/ exclusion criteria. To be included in the review, the articles had to: (1) be available as a full article in English, (2) be original research papers, (3) study human subjects within PD populations and to not assess a specific subgroup within PD, (4) be conducted in Asia, (5) not include mixed ethnic groups, and apply the NMS Quest and/ or NMSS and (6) to give the results as percentages (Fig. 1).

In addition, we undertook an initiative and global survey via the Non-Motor-PD-Study Group (NM-PD-SG) Early Career subgroup, which enabled us to ascertain the formalised linguistic validations of the NMS tools in Asian countries.

\section{Non-Motor Symptoms Questionnaire}

The NMS Quest was the first validated tool that specifically assessed NMS in a holistic manner. It is a self-completed questionnaire in a "yes" and "no" fashion that can be easily completed by the patient or carer. In total, 30 different NMS encapsulating various domains of NMS are captured [10].

\section{Non-Motor Symptoms Scale}

NMSS is a healthcare professional-completed scale capturing the severity (mild, moderate, and severe) and frequency (every day, several times a week, once a week, and rarely) of 30 different NMS divided into 9 distinct domains [16]. Both tools are recommended by the MDS and other learned societies for holistic assessment of NMS and their burden.

\section{Results of Individual Studies Using Non-Motor Symptoms}

Questionnaire

The NM-PD-SG Early Career subgroup global survey initiative identified that translations of NMS Quest were available using linguistic validation in Malay, Chinese (mandarin), while investigator translated use of NMS Quest was reported from Korea, Thailand, and India [98].

In total, we identified 12 studies that applied the NMS Quest to assess NMS in patients living in Asia and also met all other inclusion criteria (Fig. 1). The majority of studies were conducted in China, one in Korea, one in Thailand, one in Taiwan, one in Turkey, and one in India.

One of the first to address NMS in Asia were Cheon et al. [17], who conducted a survey in Korea by applying the NMS Quest to 74 treated PD patients. The most common NMS was nocturia (67.6\%). Furthermore, patients frequently reported restless legs (RL; 66.7\%), (although RL was not assessed using international criteria); constipation (65.8\%), feeling sad (65.3\%), orthostatic dizziness $(63.9 \%)$, and memory problems $(60.8 \%)$. Bowel incontinence $(5.4 \%)$, delusions $(8.3 \%)$, and hallucinations (17.6\%) were reported least frequently. About $98.7 \%$ of the population reported at least one NMS with an average of 12.4 NMS per patient.

Wang et al. [18] analysed the NMS profiles of 117 Chinese patients and found the most commonly reported NMS was constipation $(55.6 \%)$ followed by problems remembering things (41.4\%) and feeling sad (43.2\%). The least commonly reported NMS included bowel incontinence, vomiting, falling, and delusions.

Subsequently, Yu et al. [19] recruited 90 consecutive PD patients as well as sex and age-matched stroke, diabetes, and heart disease patients from Shandong University, China. On average, PD patients reported 12 different NMS. Nocturia (77.1\%), constipation $(70 \%)$, feeling sad $(67.8 \%)$, forgetfulness $(66.7 \%)$, anxiety (60\%), RL (60\%), insomnia (55.6\%), loss of interest, sexual dysfunction $(53.3 \%)$, and intense vivid dreams (52.2\%) were the most commonly reported NMS.

Zhou et al. [20] reported that $230 \mathrm{PD}$ patients attending an outpatient clinic in Shanghai, China, had a high prevalence of constipation (64.3\%), impaired memory (63\%), and nocturia (61.7\%). 
Fig. 1. Chart summarising the literature research strategy and application of inclusion/exclusion criteria. PD, Parkinson's disease; NMS, non-motor symptoms; N, number; NM-PD-SG, Non-Motor - Parkinson's Disease - Study Group; MDS, Movement Disorder Society.

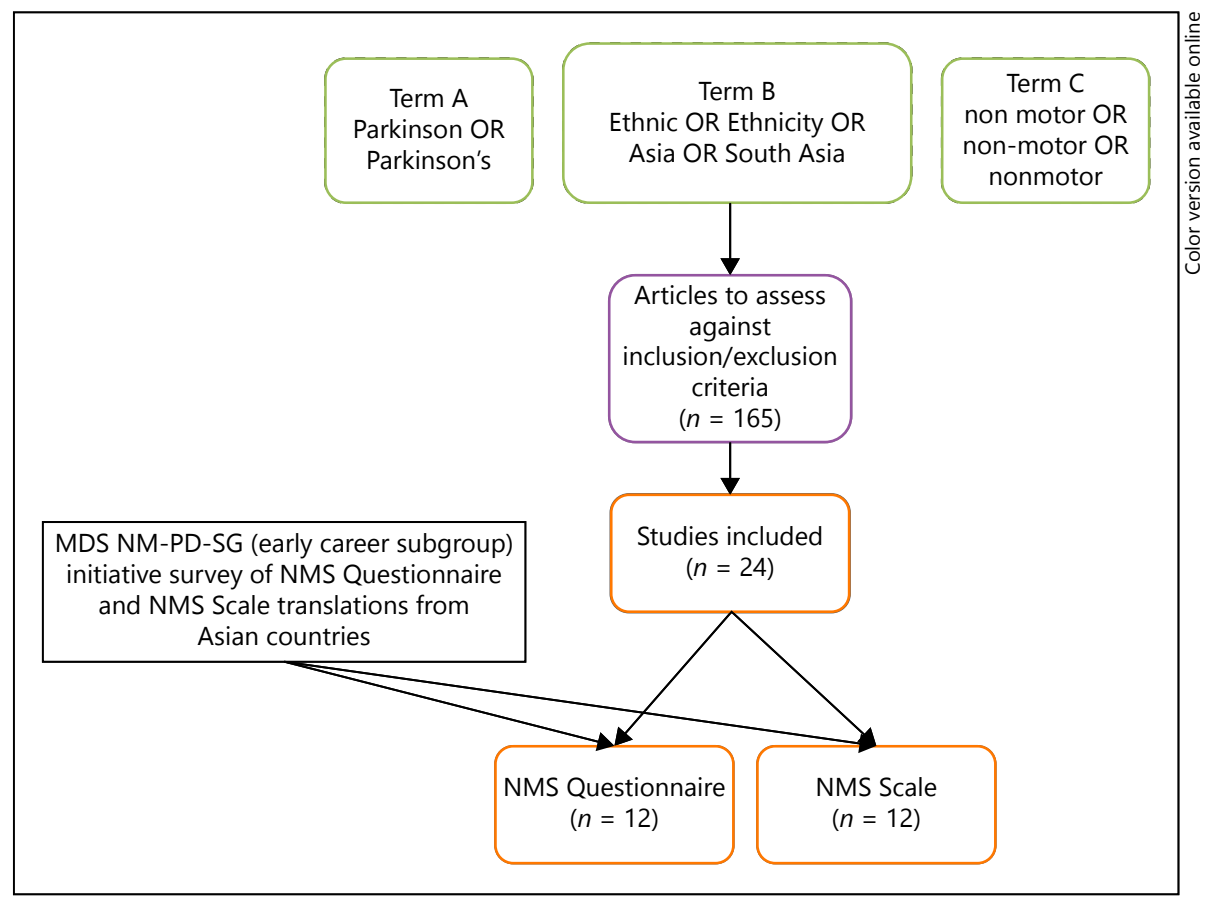

Gan et al. [21] conducted another study in Shanghai, China. They found that out of 155 patients, on average each reported 8 different NMS using the NMS Quest. The most commonly reported NMS include memory problems (65.8\%), constipation (64.6\%), and nocturia (61.4\%). Vomiting, bowel incontinence, swelling of legs, and diplopia were the least frequently reported NMS in less than $10 \%$ of assessed patients.

A study conducted in Thailand [22] found that NMS are very common in Thai patients with virtually all reporting at least one NMS. On average, patients self-reported 9.5 NMS. The most commonly reported NMS were nocturia $(64.2 \%)$, dizziness $(60.6 \%)$, and forgetfulness (56.4\%).

Li et al. [23] analysed 1,225 Chinese patients, of which $13.3 \%$ $(n=163)$ had a LRRK2 mutation. Among the entire population, they found that on average the patients reported 8.7 NMS with almost all (97.6\%) reporting at least one NMS. The most commonly reported NMS were problems with memory (56.1\%), constipation (55.3\%), and daytime sleepiness (46.0\%). The least frequent were bowel incontinence (3.3\%) and delusions (6.4\%).

Another study conducted in China [24] identified that $98.9 \%$ of 493 patients reported at least one NMS on the NMS Quest. Most patients reported problems with memory $(68.6 \%)$, constipation (57.2\%), and concentration (55.4\%). The least common NMS was delusion $(4.5 \%)$.

Li et al. [25] conducted a cross-sectional study in China reporting that among 82 patients, memory impairment (95.1\%) was the most commonly reported NMS, followed by nocturia ( $86.6 \%)$ and intense vivid dreams (82.9\%). The least commonly reported NMS were bowel incontinence, falling, and swelling of legs.

A team from Hyderabad, India, assessed the NMS of 53 general PD patients and compared them with patients who had undergone deep brain stimulation [26]. They found that $98 \%$ of patients who did not undergo deep brain stimulation reported at least one NMS. Nocturia, pain, and constipation were the most frequently reported NMS $(83,77.3$, and $71.7 \%$, respectively). Diplopia, delusions, and swelling of legs were the least frequently reported NMS.

A Turkish team conducted a small-scale study in which they found memory problems (87\%), nocturia (82.6\%) alongside constipation, urinary urgency, pain, concentration, and depression (all 73.9\%) to be highly prevalent among their cohort of 23 patients. Bowel incontinence, delusions, and dribbling were least commonly reported NMS, consistent with other studies [27].

Lastly, Liu et al. [28] found in a Taiwanese cohort $(n=210)$ that the most commonly reported NMS were nocturia (62.7\%), constipation $(51.0 \%)$, and bowel urinary urgency $(49.5 \%)$. Bowel incontinence $(2.9 \%)$, delusions $(6.2 \%)$, and hyperhidrosis (10.5\%) were the least prevalent.

\section{Synthesis of Results}

Table 1 shows the key data from included studies, and Table 2 summarises the most $(>60 \%)$ and least $(<40 \%)$ frequent NMS on the NMS Quest. The cut off points were chosen in an arbitrary fashion.

\section{Results of Individual Studies Using the Non-Motor Symptoms} Scale

The NMSS was used in a translated fashion in Malay and Chinese [98].

In total, we identified 12 studies which met all inclusion criteria applying the NMSS (Fig. 3). The majority of studies were conducted in China, alongside 3 studies in Korea, one in Singapore, and one in India.

Kim et al. [29] analysed the NMS profiles of 23 drug naïve Korean patients and compared them with healthy controls. They found the most frequently reported NMS domains to be urinary 


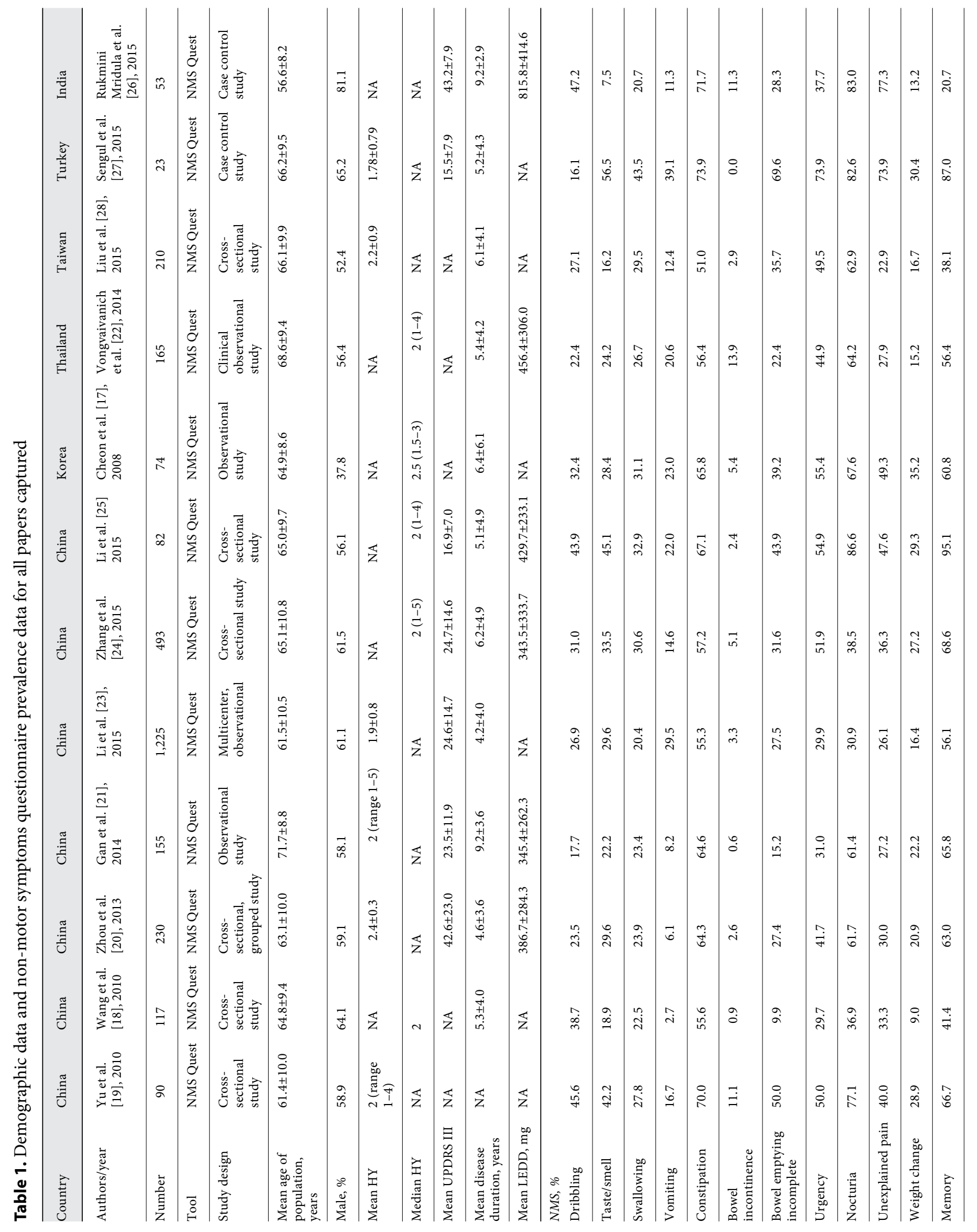




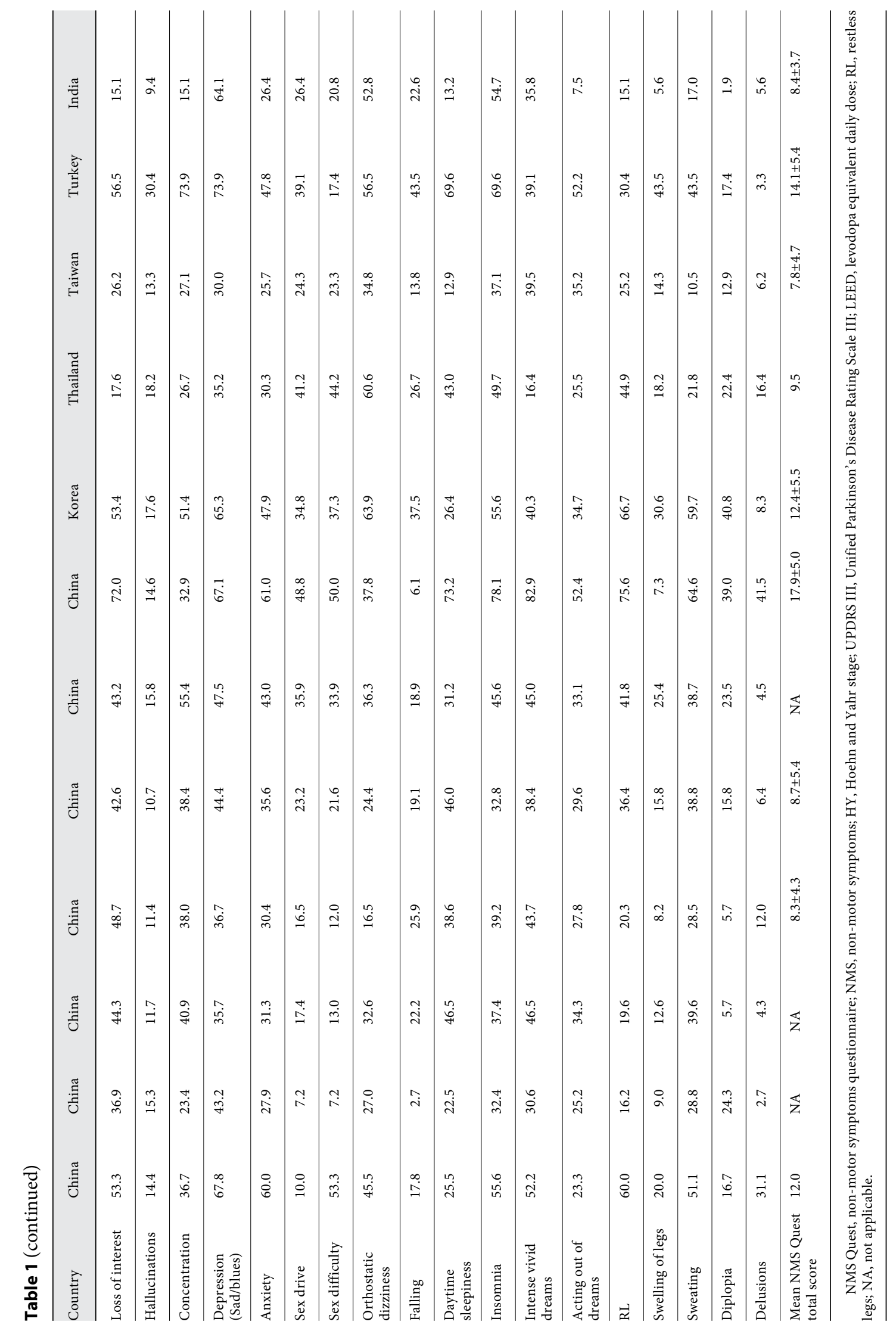




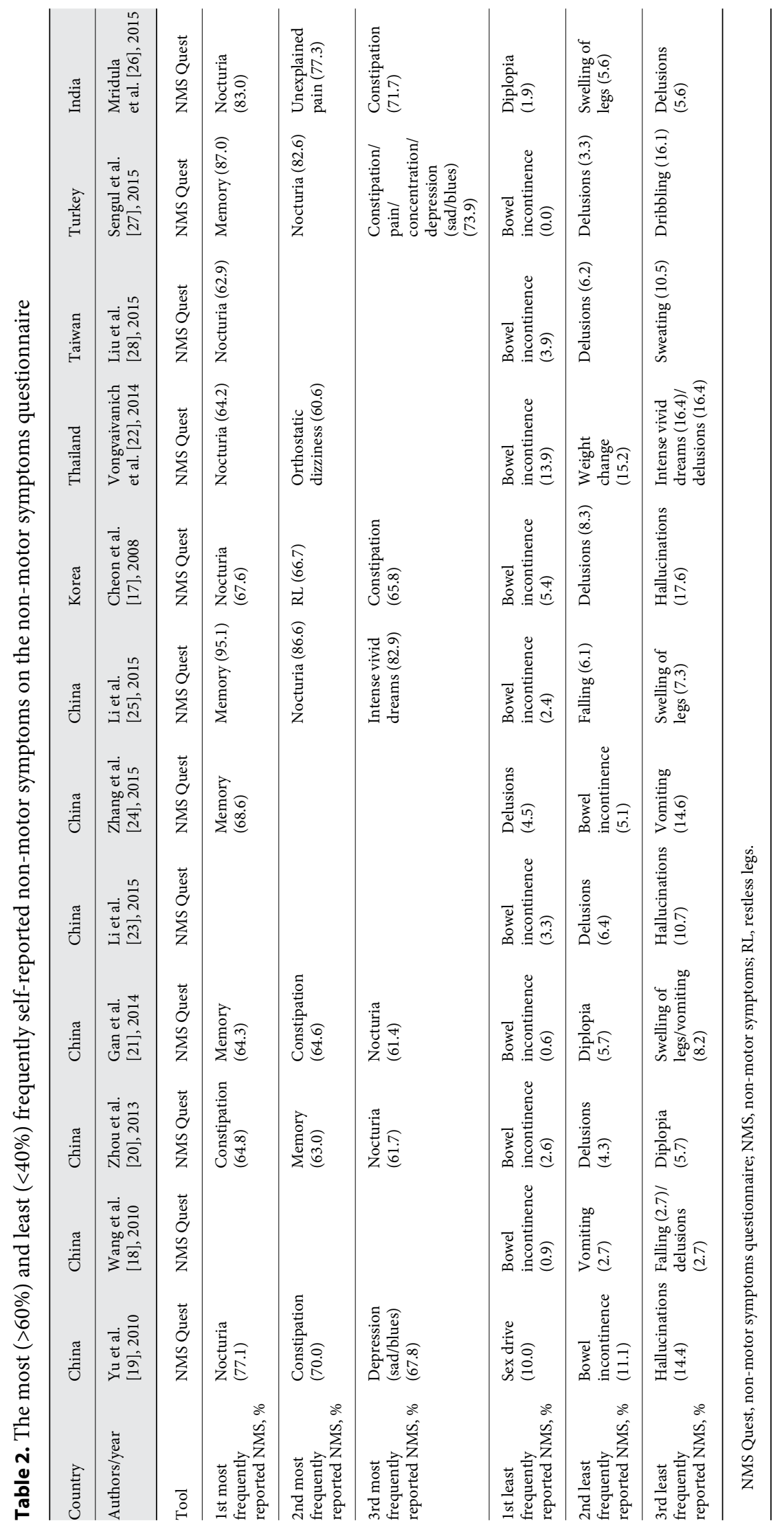


Fig. 2. Possible impact of ethnicity on the expression of non-motor symptoms. H. pylori, Helicobacter pylori; COMT, catechol$\mathrm{O}$-methyltransferase.

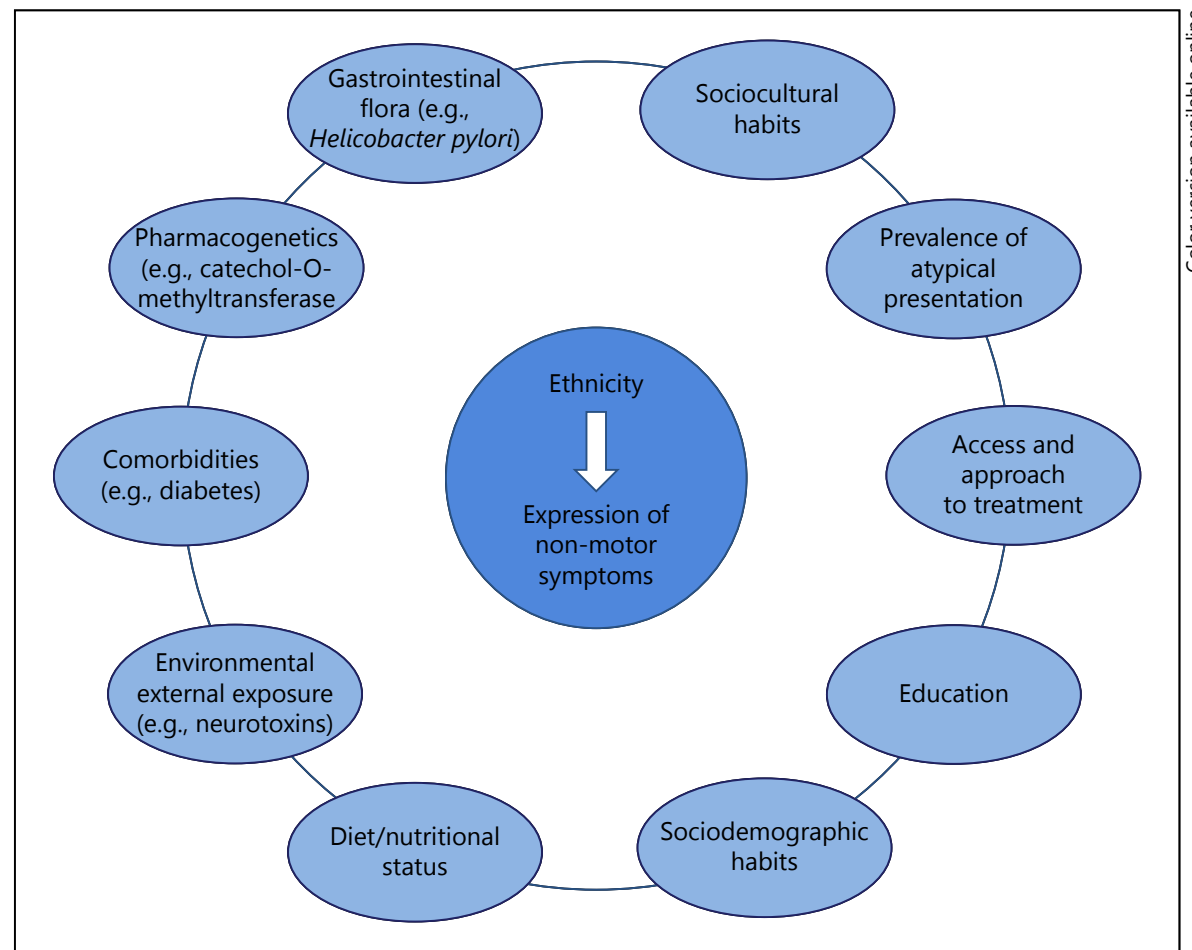

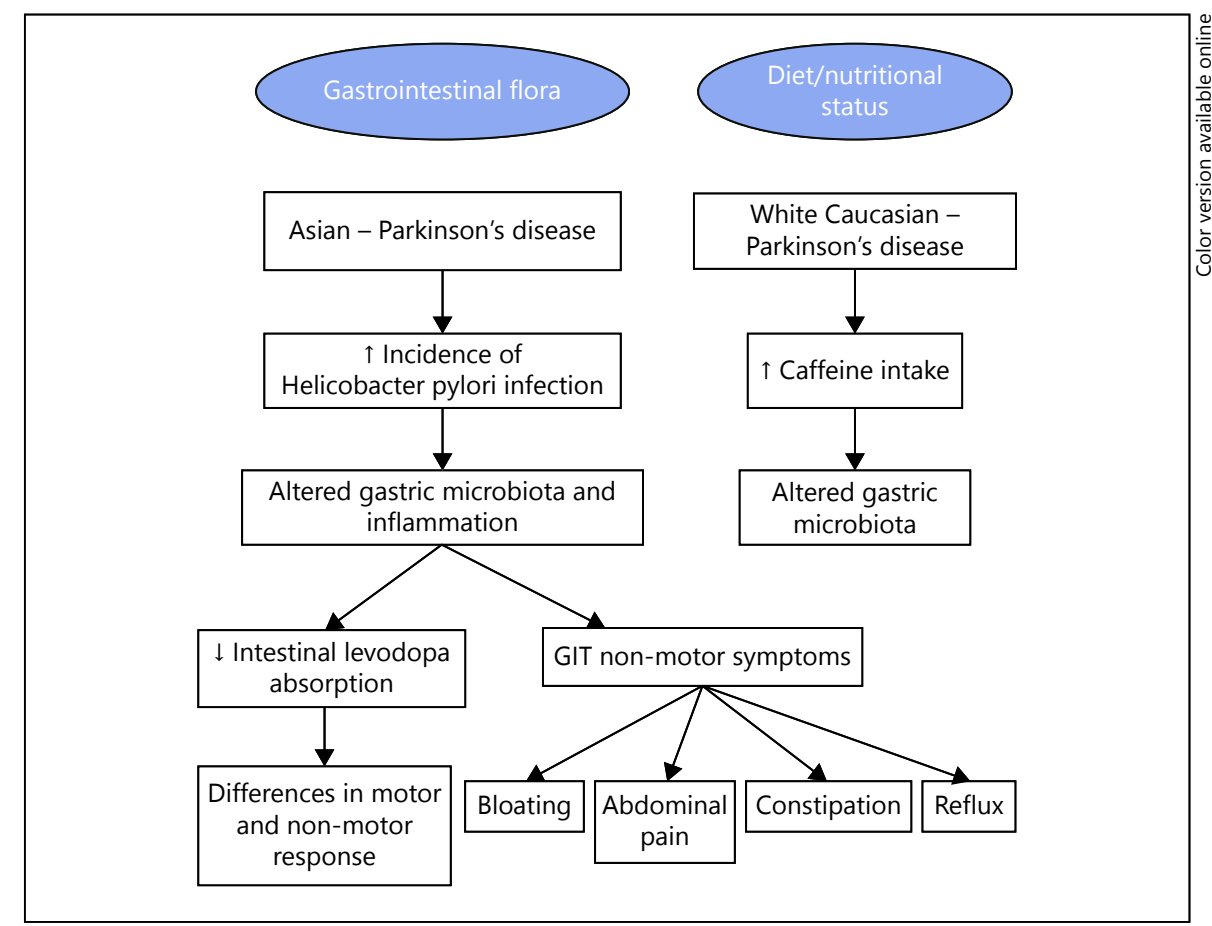

Fig. 3. Speculated causes underlying gastrointestinal non-motor symptoms in Parkinson's disease across different ethnic groups. GIT, gastrointestinal.
(86.9\%), attention/memory problems (86.6\%) as well as problems with mood/apathy $(82.6 \%)$. In detail, it is important to mention that $52.2 \%$ of the included patients reported problems with RL.

Kim et al. [30] investigated and assessed NMS in 131 South Korean PD patients against 129 age- and gender-matched healthy controls. The authors reported that all patients of their South Korean cohort reported at least one NMS; the NMSS domains of sleep/fatigue (89.3\%), sexual dysfunction (84.7\%), and attention/ memory $(81.7 \%)$ being the most frequent. However, mood/apathy, gastrointestinal, urinary, and miscellaneous symptoms were 
also highly prevalent here. The lowest reported NMS was the domain perception at $32.1 \%$.

Kim et al. [31] conducted a study in Korea that partly confirmed the previous results by Kim et al. [29]. Mood/cognition (81.7\%), sleep/fatigue $(80.0 \%)$ as well as miscellaneous NMS including pain, change in ability to taste and smell, change in weight, and excessive sweating (72.8\%) were among the most frequent NMS domains.

Krishnan et al. [32] assessed NMS profiles in India using the NMSS. Their findings showed that compared to an age-matched group of healthy controls, virtually all Indian PD patients reported at least one NMS on the NMSS. The most common NMS were among the sleep/fatigue domain (89.7\%), followed by $\mathrm{mood} / \mathrm{cog}$ nition $(88.5 \%)$ and miscellaneous $(80.5 \%)$. The least common NMS domains were cardiovascular (44.8\%) and perceptual problems/hallucinations (44.8\%).

Guo et al. [33] analysed 616 Chinese patients, who on average reported 9 different NMS, with only $4.9 \%$ of patients not reporting any. The most common NMS domains were sleep and fatigue (77.3\%), attention and memory (68.0\%), mood and apathy $(64.3 \%)$, miscellaneous $(62.7 \%)$, in particular pain $(39.4 \%)$, and finally gastrointestinal symptoms (54.4\%). The problems least frequently reported by patients were sexual dysfunction $(27.3 \%)$, cardiovascular problems $(26.0 \%)$ as well as perceptual problems/hallucinations (18.7\%).

In a further study, Guo et al. [34] analysed 522 Chinese patients and identified that sleep/fatigue (76.6\%), followed by attention/ memory (67.8\%), mood/apathy (65.1\%), and miscellaneous $(61.5 \%)$ were the most commonly reported NMS domains. Again, $95.2 \%$ of the total population reported at least one NMS.

Song et al. [35] found that the most commonly reported NMS among a 693 Chinese PD cohort were problems within the domains of sleep/fatigue (79.8\%), attention/memory (69.8\%), mood/ apathy $(65.7 \%)$, and miscellaneous $(64.9 \%)$.

Another prospective study from China by $\mathrm{Ou}$ et al. [36] demonstrated that sleep/fatigue $(89.7 \%)$, attention/memory (83.3\%), and urinary (71.8\%) domains were the most commonly affected.

Furthermore, Ou et al. [37] showed in a subsequent study that sleep/fatigue (88.9\%), miscellaneous $(77.8 \%)$, and mood/apathy (66.7\%) were among the 3 most frequently reported domains.

Wu et al. [38] and Zhang et al. [39] published their results with well-sized cohorts from China. Both reported similar NMS prevalence across many domains with sleep/fatigue once again being highest at 79.7 and $83.2 \%$, respectively, mood/apathy (both $67.1 \%$ ), attention/memory (63.1 and 67.1\%), and miscellaneous (62.8 and $68.5 \%)$. It is noteworthy that perceptual difficulties were reported in an infrequent fashion (10.3 and $14.5 \%$ respectively), concordant with previous studies.

Yong et al. [40] compared a 200 strong cohort of Singaporean patients to 150 healthy controls. The authors found sleep/fatigue (83.9\%), attention and memory (69.9\%), and mood/apathy (68.6\%) to be the most prevalent NMS domains. Issues with perception (17.3\%) and cardiovascular systems $(27.1 \%)$ were found to be the least frequently reported.

Synthesis of Results

Table 3 shows the key data from the included studies, and Table 4 summarises the most $(>60 \%)$ and least $(<40 \%)$ prevalent NMS on the NMSS.

\section{Discussion}

To our knowledge, this is the first review comparing different studies on NMS profiles of PD patients across Asia that were assessed with validated tools (NMS Quest and NMSS), the translation of tools being identified by a specific global survey of the MDS Early Career subgroup of the NM-PD-SG.

\section{Our Literature Review Reveals the following Key Findings}

- The self-reporting of NMS, as well as the overall occurrence within PD patients in Asia is high. This is similar to studies consisting primarily of Western/White Caucasian PD patients.

- Symptoms of nocturia, constipation, and memory impairment appear to be most frequently self-reported NMS on the NMS Quest.

- Generally, symptoms within the domains of sleep/fatigue, attention/memory, and mood/apathy appear to be the most prevalently reported when using the NMSS.

- Symptoms of bowel incontinence, delusions, and impaired sex drive appear to be the least frequently reported NMS by Asian patients with PD.

We have focused on NMS because of its key importance in the prodromal and clinical stage, as well as the pathophysiology of PD [5, 41]. NMS subtypes are now recognised, and the implicated neuropathology reflects the clinical expression [42-44]. In addition, NMS are a key determinant of QoL [45]. In spite of this, awareness of NMS remains low in many Asian countries where PD is still largely regarded as a motor syndrome only. Several studies in Europe and other countries performed holistic assessments of NMS, and have outlined important unmet needs in PD care [46]. Studies in Asian cohorts were, therefore, needed and this review reveals that high levels of NMS, as well as some differences in NMS in both occurrence and pattern, are evident.

Systematic and comprehensive rather than individual assessment of NMS is now possible internationally with the introduction of either a self-reported tool such as the NMS Quest or a health professional administered tool (NMSS) [47].

NMS as a whole appear to be universally prevalent across Asia, and the results obtained match very closely to the reports in Western countries with more than $90 \%$ of patients reporting at least one NMS. Such examples include studies in India [26, 32], Taiwan [28], China [36, 37, 48], and Korea [31]. 


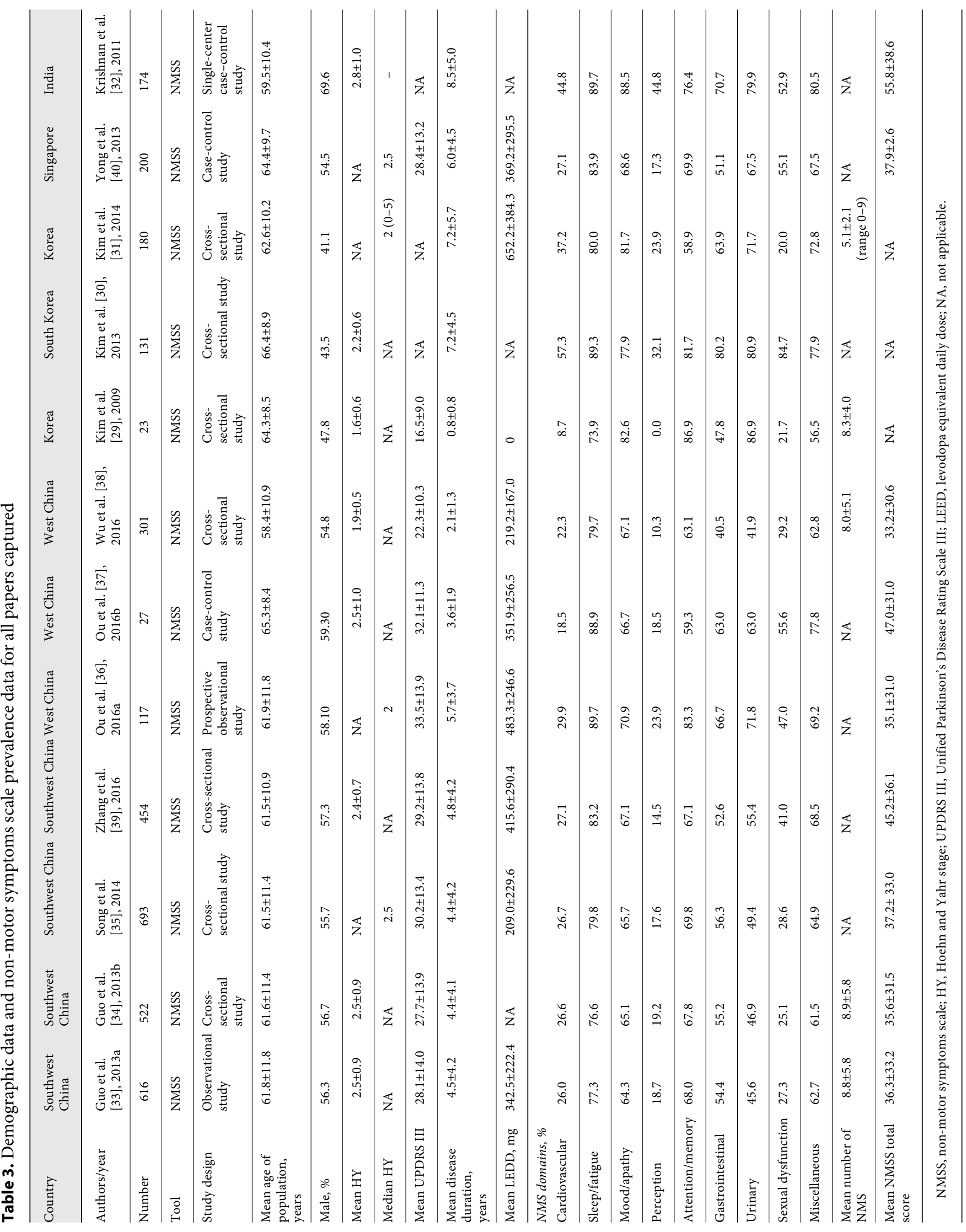




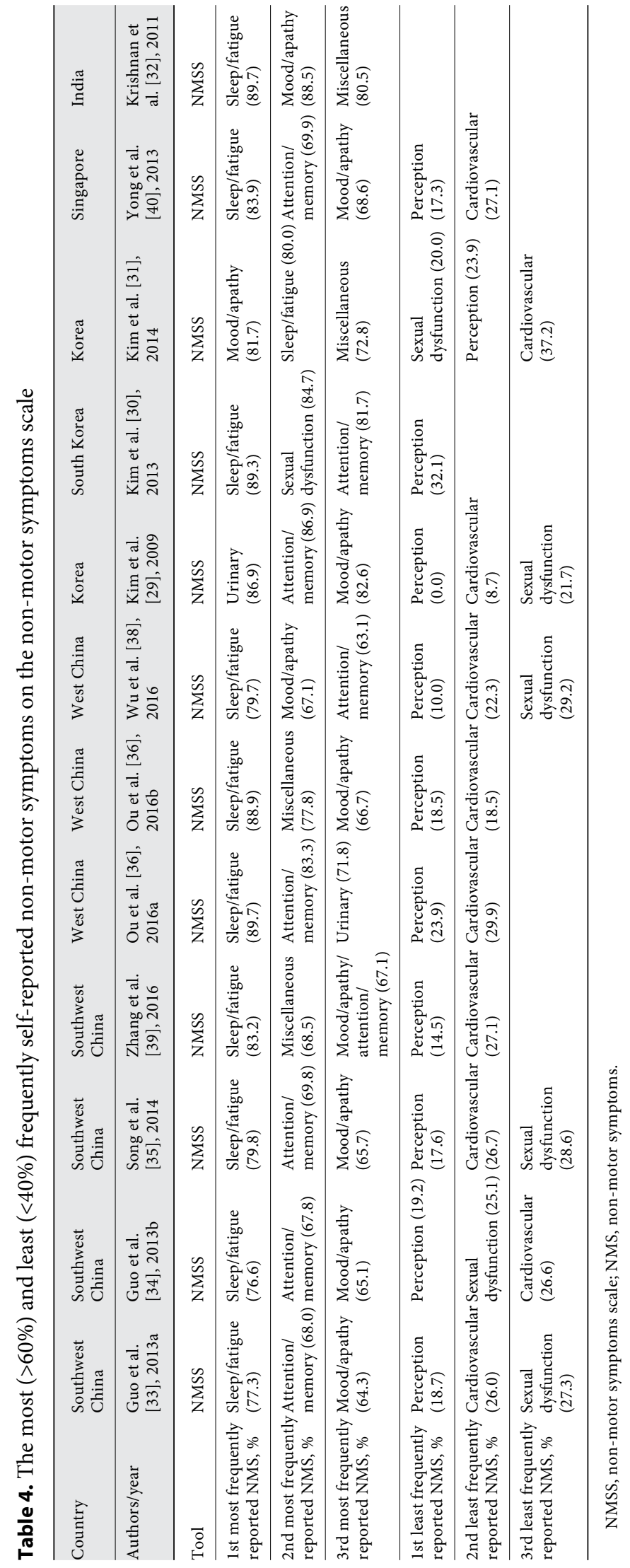

Using the NMS Quest across Asia, constipation was among the 3 most prevalent NMS in all included studies except a study in China (67.1\%) [25] and in Thailand (56.4\%) [22]. However, even in those studies constipation was reported in more than half of the included population. Similar results, with a prevalence of $78.4 \%$, were obtained in Japan in a study by Tsuboi et al. [49]. The firstin-Japan large-scale observational study addressing NMS (J-FIRST) including more than 1,000 PD patients which applied the MDS UPDRS for the assessment of NMS and also showed that constipation was the most commonly reported NMS with a prevalence of 79.7\% [50].

In terms of controlled data from Western PD population, the validation study of the NMS Quest conducted by Chaudhuri et al. [10] reported a lower prevalence of constipation (46.7\%) compared to the reported data in Asia.

In addition, international work by Martinez-Martin et al. [51] reported a lower prevalence of constipation with $52.5 \%$. However, the cause of this unclear. Some possible explanations will be discussed below.

Besides constipation, memory impairment appears to be one of the 3 most frequently self-reported NMS in Asia (compared with data collected by Chaudhuri et al. [10] [43.9\%] and Martinez-Martin et al. [51] [44.85\%]). A recent study by Yu et al. [100] using the Chinese translation of the MDS UPDRS also concluded that NMS among Chinese populations are mostly related to cognitivebased symptoms.

Self-reported memory issues are difficult to quantify and when the data are compared to NMSS (frequency and severity rated) cognitive domain, studies also reported problems in the cognitive and apathy domain $(>60 \%$; Table 4). With the exception of one study in Korea [31], and the study in India [32], all other studies reported attention/memory as one of the most reported NMSS domain. This, however, does not prove that there is a greater rate of mild cognitive impairment or dementia in these populations as such observations can only be made after systematic examination with specific validated tools, which were not available in the reported studies [52]. A myriad of factors influence memory and cognition in PD, which range from genetics to lifestyle, all of which need to be considered in systematic studies in the future. There is also a high rate of use of anticholinergic drugs in many Asian countries for PD. Anticholinergics may aggravate cognitive decline and their role therefore needs to be examined [53].

Thirdly, our review suggests that nocturia was reported among the top 3 NMS. Chaudhuri et al. [10] and Martinez-Martin et al. [51] demonstrated that over $60 \%$ of 
patients reported nocturia. This data is largely concurrent with the Asian data presented in this review.

Rana et al. [11] suggested that immigrant Asian patients may be at higher risk of developing nocturia, although this study did not address indigenous populations in Asia. Nocturia appears to be commonly self-reported, regardless of ethnic and cultural background. In spite of this high rate, nocturia remains a poorly studied and managed NMS, and its global prevalence should prompt treatment-based trials.

Other western studies include a study by Romenets et al. [54] who analysed NMS Quest data from 70 patients in Quebec. In the patients assessed, 77.9\% reported NMS of urinary urgency, $66.7 \%$ insomnia, $77.3 \%$ loss of taste/smell.

Depression and RL were also frequently reported in Asian cohorts, with RL being substantially higher compared to most Western studies [17, 19, 25]. The rates quoted with NMS Quest are particularly high, and this may be spurious because of the way the questions are explained to patients, cultural differences, attitude towards $\mathrm{RL}$, and possible overlap with akathisia. Studies using RLstandardised tools have generally reported low rates in Asian populations [99]. As such, further studies involving several Asian countries to address RL in a controlled population versus treated $\mathrm{PD}$ are required.

Studies applying the NMSS reported sleep/fatigue and mood/apathy among the 3 top domains. It is worth noting that the study in India, one study in Korea, and 2 studies in China reported miscellaneous among the top 3 NMSS domains.

The least frequently captured NMSS domains were perceptual impairment, cardiovascular impairment, and impairment in sexual drive and ability to have sex when trying. Again on the NMS Quest, the least frequently reported NMS included bowel incontinence and delusions followed by hallucinations, vomiting, diplopia, altered sex drive, and difficulty when engaging in sex, which is in line with the findings on the NMSS.

The NMS Quest validation study reported the least frequent symptoms were bowel incontinence (4.9\%), vomiting $(8.1 \%)$, and delusions (12.3\%), which is in line with the findings in the Asian studies [10].

Western studies have established the defining role of NMS in the determination of QoL, and a similar impact is also observed within the Asian PD population. Li et al. [55] demonstrated, in a cross-sectional study in China, that the domains of sleep/fatigue, mood, gastrointestinal, urinary, and miscellaneous had a particularly meaningful negative impact on the patient's QoL. A study from Singapore [56] reported that sleep, mood, and attention dis-

NMS in PD Living in Asia orders have a significant negative impact on QoL, which is similar to data from Europe [57]. Given that these were the NMS we identified to be most prevalent in Asian patients, it emphasises its importance, the need to address them in clinical practice, and the possible future requirement of ethnicity-based personalised medicine [56].

\section{Intra-Ethnic Differences}

NMS Quest values reported by Li et al. [25] in China are higher than those reported in other Asian studies. As a possible explanation, the authors highlighted the wide range of different economic and social environments and set ups, including medical facilities and provision between developed and non-developed parts of a country (pharmacoeconomic aspect of personalised medicine) [58].

Data from China and South Korea underpin 2 such examples. First, when considering variability within specific countries, the 7 Chinese cohorts report similar NMSS scores across all 9 domains. This finding is observed with the exception of the sample by Ou et al. [36], who report consistently higher prevalence of NMS across all NMSS domains compared to the data from the other 6 Chinese cohorts. It is not clear why this may be so, however, it could be driven by a relatively more advanced stage of PD (mean disease duration of 5.7 years, a mean UPDRSIII score of 33.5, and a mean levodopa equivalent daily dose of $483.3 \mathrm{mg}$ ). Furthermore, the 3 included papers from Korea using the NMSS are discordant, particularly across sexual function and perceptual problem/hallucination domains. It has to be acknowledged that there are considerable sampling differences and for instance, the study by Kim et al. [29] only includes drug naïve patients where NMS may be different to advanced PD [59]. Additionally, other studies show large disparity in sample sizes (varying between 23 and $180 \mathrm{PD}$ patients). However, the high rates of sexual dysfunction in the cohort reported by Kim et al. [30] is surprising and needs to be evaluated further.

\section{Possible Explanations for Observed Ethnic Variations}

It is most likely that the disparities observed among different ethnic groups are multifactorial, as shown in Figure 2.

One factor that certainly needs to be taken into account are the sociocultural differences between countries and cohorts studied. A tempting explanation would be to consider the important role that differences in diet, exercise, nutritional status, comorbidities, and gastrointestinal flora may play. Wang et al. [18] reported that more than $22 \%$ of their Chinese cohort was malnourished or 
at risk of malnutrition. It is, therefore, suggested that malnutrition has a negative impact on NMS, which plays an important role in the interpretation of ethnic differences. Additionally, education in dietary and living habits might vary considerably between ethnic groups and may therefore at least partially account for the differences [18]. Preliminary results from a multicenter study in London have reported higher alcohol and caffeine consumption among white Caucasian PD patients living in London compared to Asian patients resident in the UK, Indian patients living in India and Thai patients living in Thailand [14]. Coffee has been reported to influence the gastrointestinal microbiota and might at least partly drive the observed differences in gastrointestinal NMS [60]. Azmin et al. [61] reported in a study from Malaysia (more than two thirds of patients were Chinese, followed by Malay and Indian patients), that constipation was among the most prevalent NMS. The authors concluded that the high prevalence of Helicobacter pylori infection in Malaysian populations might play a role and also suggested that gastrointestinal dysfunction maybe more prevalent in Asian populations compared to Western populations (Fig. 3). Differences in dietary habits between the East and the West might also be a factor that needs to be addressed [61]. A further confounding variable that needs to be taken into account is the profile of comorbidities. It has been reported that Asians have a stronger ethnic and genetic risk to develop diabetes mellitus. As a consequence, diabetes mellitus (type 2) is widely prevalent in Asia and has an increasing trend [62]. Diabetes mellitus might lead to autonomic disturbances and might be associated with the development of constipation and nocturia. Similarly, prostatic disease might play a key role in the development of nocturia; however, the prevalence among different ethnic groups still needs to be explored.

A further argument for why ethnic differences might occur could be related to the fact that different sociodemographic and education levels are likely to influence the awareness and understanding of PD. It has been shown that education level has a significant impact on the clinical presentation of symptoms in PD [63]. Health beliefs have also been related to cultural differences, and therefore might influence the perception of PD and individual symptoms. Consequently, this may also impact the presentation [64]. Access to medical care and in particular to neurologists is highly variable across different Asian countries and also could influence the expression of NMS. Li et al. [23] identified that every PD patient reported at least one NMS, and this high prevalence might be ex- plained by late referrals and insufficient knowledge about $\mathrm{PD}$, which is in line with the conclusions drawn by Zhang et al. [24].

A large clinical survey of 901 patients from 4 different regions in China identified that patients take lower doses of dopaminergic drugs, and subsequently have less drug-induced complications compared to Western populations [65]. The development of dyskinesia has been reported to be significantly lower compared to Western countries [66]. Some of these observations match the findings reported by Chaudhuri et al. [2] in South Asian cohorts living in the UK, particularly in relation to the described motor phenotype. Interestingly, the authors discussed that low doses of medication might be related to the attitude towards medication in China, which has been described as "a small stream runs far" and is also reflected in the Chinese PD treatment guidelines [67].

The lower dose of dopaminergic drugs may presumably also have an impact on drug-related side effects, such as impulsive compulsive behaviours (ICDs) $[68,69]$. In this review, we cannot comment on the differences in ICDs between different ethnic groups, as it was not systematically recorded in the included studies. Data from the NMS Quest and NMSS only address sexual drive as part of ICD; however, it is not clear if patients reported an increase or decrease in sexual drive.

Medications such as anticholinergic drugs are still widely used across the Asian continent because of their relatively low cost compared to other anti-Parkinsonian medications. Again, this is an important aspect to consider when interpreting the differences in PD profiles in particular features, such as cognitive impairment, urinary problems, and constipation [70]. As already highlighted by Gan et al. [21], given that constipation and urinary side effects are known side effects of anticholinergic medication, this might at least partly explain the higher rate of constipation among Asian PD patients.

The study by Chaudhuri et al. [2] was the first to report a 3-fold higher rate of levodopa "hypo" responsiveness in South Asian patients living in the UK. Our current review dataset suggests that the mean levodopa equivalent daily dose is low across the Asian populations except in one study in India and one from Korea. This observation, therefore, does not support the original findings of Chaudhuri et al. [2]; however, it might be explained by the different attitudes towards Parkinsonian drugs, as discussed. Another key complication of levodopa therapy is that motor fluctuations usually manifest as "wearingoff." Bhidayasiri et al. [71] summarised the management
Sauerbier et al. 
of these wearing-off symptoms in Asia, and evident cultural differences were also observed compared to Western countries.

Differences in underlying genetic variants have also been reported to alter the clinical profile among different ethnic groups.

Peeraully and Tan have discussed that there are genetic differences in sporadic PD between East and West [72]. Huang et al. [73] highlighted under-investigation of the genetic origins of described differences. For instance, LRRK2 mutations have shown to be more prevalent in white Caucasian compared to Asian patients. However, Li et al. [23] concluded in their study that genetic differences might not play a key role in the presentation of NMS. This, therefore, requires further investigation.

Furthermore, the GBA genotype at rs6812193 Single Nucleotide Polymorphism is known to be associated with PD, particularly in Ashkenazi Jewish PD patients [74]. A review by Chen et al. [66] addressed the association between GBA mutations and PD in Chinese patients living in Singapore [75], Taiwan [76-79], and China [8084]. Unlike Ashkenazi Jewish patients, who present with a higher prevalence of the N370S mutation, in the included Chinese population the L444p mutation appeared to be significantly associated with PD. No further conclusions could be drawn due to the small sample sizes $[84,85]$.

GBA mutation-positive PD presents with a characteristic clinical presentation including a higher NMS burden related to cognitive impairment compared to non-carriers $[18,24,86]$. Specifically, GBA-carriers developing PD have a more rapid progression of cognitive impairment, a higher prevalence of domain-specific impairment in visual memory tasks, and a higher degree of psychiatric symptoms [87]. The psychiatric features that have been reported to have an increased prevalence are depression and anxiety as well as hallucinations and delusions but studies have reported conflicting findings [85]. It remains to be elucidated if there are ethnic differences in the NMS in PD-GBA and LRRK2-carriers [87].

Furthermore, the COMT enzyme that is important to metabolise dopamine has been shown to have a trimodal distribution. This distribution is seen phenotypically with one group expressing a higher activity (COMTVal/Val), which translates into a fast metabolism of levodopa, a second group with intermediate activity (COMTVal/Met) and one with low activity (COMTMet/Met) [88-90]. Ethnic variations in COMT activity have been observed, such as a higher prevalence of the high activity variant in African people, and this issue therefore needs to be further investigated in future studies within Asian cohorts [9193].

It has been suggested that polymorphisms of the Taq1A gene are related to the differential presentation of hallucinations in PD patients with a higher rate among white Caucasian [94] compared to Chinese populations $[85,58]$.

In addition, ethnic differences in the specific polymorphisms of dopamine receptors have been described with an increased risk of developing ICD. This association is particularly notable in PD populations across Malaysia [95].

The above discussed potential factors link well with the newly emerging concept of holistic personalised medicine for PD, as has been recently outlined by Titova et al. [58].

\section{Limitations}

We need to acknowledge that the cited studies in Asia vary widely in methodology and sample characteristics, and most studies included were largely "convenience sampling" and targeted, rather than true populationbased studies. Hence, it would be premature to make quick judgments and conclusions. Furthermore, these are mostly single-centered and non-controlled observational studies. The ethnicity-profiling methods are also unclear in many studies. As such it is difficult to make comparison between studies for statistical analyses based conclusions, but they do allow for observational interpretation. Methodological problems exist with observational studies, such as selection bias, information bias, and confounding. However, observational studies are both important and able to give accurate insight into specific observation [96], particularly when several large-scale studies report similar observations, such as the common occurrence of nocturia.

Although we focused on studies using NMSS and NMS Quest only and thus stratified the papers reviewed, there is still inconsistency regarding the way these tools are delivered. As identified by the NM-PD-SG Early Career initiative, some were translated by investigators while others were locally translated and very few underwent approved formalised linguistic validation. Furthermore, we need to acknowledge that there are local translations in several Asian countries which have not been captured by our methods. Variability of data reporting could, therefore, result from this limitation.

In conclusion, this review supports previous observations that NMS are highly prevalent within Asian PD populations with some specific NMS including consti- 
pation, memory impairment, nocturia, and sleep-related disorders being notably prominent. It appears that NMS profiles vary between ethnicity; however, current data are controversial and there may be intra-ethnic differences.

\section{Future Directions and Implications}

As populations become increasingly diverse and multicultural, it is crucial to be aware of and respect possible differences to improve the treatment of long-term neurological conditions, such as PD. This will allow a holistic and modern delivery of individualised ethnicity-specific treatment packages. It is thus important to be aware of the specific needs and profiles of NMS in PD patients of varying ethnicity [25]. Ethnicity-related impact on motor and NMS of PD is an unmet need which requires further exploration. Diet, culture, religion, personality, body weight, pharmacogenomics, and access to medical care and management can all influence treatment and consequently the QoL of PD patients in a positive or negative manner. Titova and Chaudhuri among others have recently stressed the necessary switch to personalised medicine to achieve the best possible therapeutic effect. This can only be successful in an increasingly diverse world if we understand the differences in ethnic groups including aspects of cultural, social, environmental, and genetic differences. This review indicates that linguistic validations using standard methodology needs to be adopted where these tools are currently used.

\section{Acknowledgments and Funding}

We would like to acknowledge the Non-Motor-PD-Early Career Subgroup including Rebecca Banerjee, Roberta Biundo, Lana Chahine, Stefania Diaconu, Roberto Erro, Temitope Farombi, Sanjay Gangadharan, Miguel Grilo, Onanong Jitkritsadakul, Lisa Klingelhoefer, Antonella Macerollo, Flavia Niccolini, Gennaro Pagano, Haidar Salimi Dafsari, Nataliya Titova.

Nataliya Titova, Lisa Klingelhoefer, Roberto Erro, and Rebecca Banerjee led the Asian validation of NMS Quest/NMSS data collection initiative.

We would like to acknowledge funding from Parkinson's UK and Kirby Laing Foundation to support Anna Sauerbier as a clinical fellow to KRC. We also acknowledge the support of NIHR London South CRN.

\section{References}

1 Kalia LV, Lang AE: Parkinson's disease. Lancet 2015;386:896-912.

2 Chaudhuri KR, Hu MT, Brooks DJ: Atypical parkinsonism in Afro-Caribbean and Indian origin immigrants to the UK. Mov Disord 2000;15:18-23

3 Chen W, Xu ZM, Wang G, Chen SD: Nonmotor symptoms of Parkinson's disease in China: a review of the literature. Parkinsonism Relat Disord 2012;18:446-452.

4 Parkinson J: An essay on the shaking palsy. Lon Med Phys J 1817:38.

5 Titova N, Padmakumar C, Lewis SJ, Chaudhuri KR: Parkinson's: a syndrome rather than a disease? J Neural Transm (Vienna) 2016, Epub ahead of print.

6 Zis P, Erro R, Walton CC, Sauerbier A, Chaudhuri KR: The range and nature of nonmotor symptoms in drug-naive Parkinson's disease patients: a state-of-the-art systematic review. NPJ Parkinsons Dis 2015;1:15013.

7 Martinez-Martin P, Rodriguez-Blazquez C, Kurtis MM, Chaudhuri KR: The impact of non-motor symptoms on health-related quality of life of patients with Parkinson's disease. Mov Dis 2011;26:399-406.

8 Jimenez-Jimenez FJ, Alonso-Navarro $\mathrm{H}$, Garcia-Martin E, Agundez JA: Advances in understanding genomic markers and pharmacogenetics of Parkinson's disease. Expert Opin Drug Metab Toxicol 2016;12:433448.
9 Marmot M, Wilkinson R: Social determinants of health. Expert Opinion Drug Metab Toxicol 2016;12:433-448.

10 Chaudhuri KR, Martinez-Martin P, Schapira $\mathrm{AH}$, Stocchi F, Sethi K, Odin P, Brown RG, Koller W, Barone P, MacPhee G, Kelly L, Rabey M, MacMahon D, Thomas S, Ondo W, Rye D, Forbes A, Tluk S, Dhawan V, Bowron A, Williams AJ, Olanow CW: International multicenter pilot study of the first comprehensive self-completed nonmotor symptoms questionnaire for Parkinson's disease: the NMSQuest study. Mov Disord 2006;21:916-923.

11 Rana AQ, Athar A, Owlia A, Siddiqui I, Awan N, Fattah A, Rana MA: Impact of ethnicity on non-motor symptoms of Parkinson's disease. J Parkinsons Dis 2012;2:281-285.

12 Cubo E, Doumbe J, Martinez-Martin P, Rodriguez-Blazquez C, Kuate C, Mariscal N, Lopez I, Noubissi G, Mapoure YN, Jon JL, Mbahe S, Tchaleu B, Catalan MJ: Comparison of the clinical profile of Parkinson's disease between Spanish and Cameroonian cohorts. J Neurol Sci 2014:336:122-126.

13 Sauerbier A, Jitkritsadakul O, Bhidayasiri R, Al-Hashel JY, Kamel WA, Kilany A, Farombi T, Martinez-Martin P, Brown R, Parry M, Martin A, Inniss R, Perkins L, Trivedi D, Klingelhoefer L, Rizos A, Dimitrov N, Zis P, Chaudhuri KR: Non-motor symptoms profiles of different ethnic groups with Parkinson's disease: a cross sectional study compar- ing the UK, Thailand, Nigeria and Kuwait. Mov Disord 2015;30:2097.

14 Sauerbier A, Jitkritsadakul O, Bhidayasiri R, Kumar H, Martinez-Martin P, Banerjee R, Kulsum M, Rizos A, Carr H, Qamar MA, Perkins L, Chiwera T, Trivedi D, Martin A, Parry M, Brown R, Al-Hashel J, Kamel W, Kilany A, Lim S, Tan A, Bhattacharyya J, Walker R, Chaudhuri KR; On behalf of EUROPAR tMNMPSGatNG: Non-motor symptoms profiles in UK white Caucasian and Asian as well as overseas Thai and East Indian patients with Parkinson's disease. Mov Disord 2016;31:829.

15 Moher D, Liberati A, Tetzlaff J, Altman DG: Preferred reporting items for systematic reviews and meta-analyses: the PRISMA statement. BMJ 2009;339:b2535.

16 Chaudhuri KR, Martinez-Martin P, Brown RG, Sethi K, Stocchi F, Odin P, Ondo W, Abe K, Macphee G, Macmahon D, Barone P, Rabey M, Forbes A, Breen K, Tluk S, Naidu Y, Olanow W, Williams AJ, Thomas S, Rye D, Tsuboi Y, Hand A, Schapira AH: The metric properties of a novel non-motor symptoms scale for Parkinson's disease: results from an international pilot study. Mov Disord 2007; 22:1901-1911.

17 Cheon SM, Ha MS, Park MJ, Kim JW: Nonmotor symptoms of Parkinson's disease: prevalence and awareness of patients and families. Parkinsonism Relat Disord 2008; 14: 286-290. 
18 Wang G, Wan Y, Cheng Q, Xiao Q, Wang Y, Zhang J, Ma JF, Wang XJ, Zhou HY, Chen SD: Malnutrition and associated factors in Chinese patients with Parkinson's disease: results from a pilot investigation. Parkinsonism Relat Disord 2010;16:119123.

19 Yu B, Xiao ZY, Li JZ, Yuan J, Liu YM: Study of an integrated non-motor symptoms questionnaire for Parkinson's disease. Chin Med J 2010;123:1436-1440.

20 Zhou MZ, Gan J, Wei YR, Ren XY, Chen W, Liu ZG: The association between non-motor symptoms in Parkinson's disease and age at onset. Clin Neurol Neurosurg 2013;115: 2103-2107.

21 Gan J, Zhou M, Chen W, Liu Z: Non-motor symptoms in Chinese Parkinson's disease patients. J Clin Neurosci 2014;21:751-754.

22 Vongvaivanich K, Nidhinandana S, Udommongkol C, Chairungsaris $\mathrm{P}$, Chinvarun $\mathrm{Y}$, Wongmek W, Suphakasem S, Suwantamee J, Sithinamsuwan P: Non-motor symptoms in Thai patients with Parkinson's disease studied at Phramongkutklao Hospital. J Med Assoc Thai 2014;97(suppl 2):S159-S167.

23 Li DW, Gu Z, Wang C, Ma J, Tang BS, Chen SD, Chan P: Non-motor symptoms in Chinese Parkinson's disease patients with and without LRRK2 G2385R and R1628P variants. J Neural Transm (Vienna) 2015;122: 661-667.

24 Zhang N, Liu W, Ye M, Cohen AD, Zhang Y: The heterogeneity of non-motor symptoms of Parkinson's disease. Neurol Sci 2015;36:577584.

25 Li HJ, Zhang MF, Chen MX, Hu AL, Li JB, Zhang B, Liu W: Validation of the nonmotor symptoms questionnaire for Parkinson's disease: results from a Chinese pilot study. Int Neurosci 2015;125:929-935.

26 Rukmini Mridula K, Borgohain R, Jabeen SA, Padmaja G, Bandaru VS, Ankathi P, Kanikannan MA, Ali Khan MS: Comparison of frequencies of non motor symptoms in Indian Parkinson's disease patients on medical management versus deep brain stimulation: a case-control study. Iran J Neurol 2015;14:8693.

27 Sengul Y, Sengul HS, Sural MK, Bakim B, Forta $\mathrm{H}$ : A comparison between rate of nonmotor symptom development in essential tremor and Parkinson's disease. Acta Neurol Belg 2015;115:289-294.

28 Liu WM, Lin RJ, Yu RL, Tai CH, Lin CH, Wu RM: The impact of nonmotor symptoms on quality of life in patients with Parkinson's disease in Taiwan. Neuropsychiatr Dis Treat 2015;11:2865-2873.

29 Kim HJ, Park SY, Cho YJ, Hong KS, Cho JY, Seo SY, Lee DH, Jeon BS: Nonmotor symptoms in de novo Parkinson disease before and after dopaminergic treatment. J Neurol Sci 2009;287:200-204.

30 Kim HS, Cheon SM, Seo JW, Ryu HJ, Park KW, Kim JW: Nonmotor symptoms more closely related to Parkinson's disease: com- parison with normal elderly. J Neurol Sci 2013;324:70-73.

31 Kim SR, So HY, Choi E, Kang JH, Kim HY, Chung SJ: Influencing effect of non-motor symptom clusters on quality of life in Parkinson's disease. J Neurol Sci 2014;347:310-315.

32 Krishnan S, Sarma G, Sarma S, Kishore A: Do nonmotor symptoms in Parkinson's disease differ from normal aging? Mov Disord 2011; 26:2110-2113.

33 Guo X, Song W, Chen K, Chen X, Zheng Z, Cao B, Huang R, Zhao B, Wu Y, Shang HF: Disease duration-related differences in nonmotor symptoms: a study of 616 Chinese Parkinson's disease patients. J Neurol Sci 2013; 330:32-37.

34 Guo X, Song W, Chen K, Chen X, Zheng Z, Cao B, Huang R, Zhao B, Wu Y, Shang HF: Gender and onset age-related features of nonmotor symptoms of patients with Parkinson's disease - a study from Southwest China. Parkinsonism Relat Disord 2013;19:961-965.

35 Song W, Guo X, Chen K, Chen X, Cao B, Wei Q, Huang R, Zhao B, Wu Y, Shang HF: The impact of non-motor symptoms on the Health-Related Quality of Life of Parkinson's disease patients from Southwest China. Parkinsonism Relat Disord 2014;20:149-152.

36 Ou R, Yang J, Cao B, Wei Q, Chen K, Chen X, Zhao B, Wu Y, Song W, Shang H: Progression of non-motor symptoms in Parkinson's disease among different age populations: a twoyear follow-up study. J Neurol Sci 2016;360: $72-77$.

37 Ou R, Song W, Wei Q, Chen K, Cao B, Hou Y, Zhao B, Shang H: Characteristics of nonmotor symptoms in progressive supranuclear palsy. Parkinsons Dis 2016;2016:9730319.

$38 \mathrm{Wu} \mathrm{Y,} \mathrm{Guo} \mathrm{XY,} \mathrm{Wei} \mathrm{QQ,} \mathrm{Ou} \mathrm{RW,} \mathrm{Song} \mathrm{W,}$ Cao B, Zhao B, Shang HF: Non-motor symptoms and quality of life in tremor dominant vs postural instability gait disorder Parkinson's disease patients. Acta Neurol Scand 2016;133: 330-337.

39 Zhang S, Ou R, Chen X, Yang J, Zhao B, Yuan X, Wei Q, Cao B, Shang HF: Correlative factors of cognitive dysfunction in PD patients: a cross-sectional study from Southwest China. Neurol Res 2016;38:434-440.

40 Yong MH, Allen JC Jr, Prakash KM, Tan EK Differentiating non-motor symptoms in Parkinson's disease from controls and hemifacial spasm. PLos One 2013;8:e49596.

41 Berg D, Postuma RB, Adler CH, Bloem BR, Chan P, Dubois B, Gasser T, Goetz CG, Halliday G, Joseph L, Lang AE, Liepelt-Scarfone I, Litvan I, Marek K, Obeso J, Oertel W, Olanow CW, Poewe W, Stern M, Deuschl G: MDS research criteria for prodromal Parkinson's disease. Mov Disord 2015;30:1600-1611.

42 Jellinger KA: Neuropathobiology of non-motor symptoms in Parkinson disease. J Neural Transm (Vienna) 2015;122:1429-1440.

43 Sauerbier A, Jenner P, Todorova A, Chaudhuri KR: Non motor subtypes and Parkinson's disease. Parkinsonism Relat Disord 2016;22(suppl 1):S41-S46.
44 Sauerbier A, Qamar MA, Rajah T, Chaudhuri KR: New concepts in the pathogenesis and presentation of Parkinson's disease. Clin Med (Lond) 2016;16:365-370.

45 Martinez-Martin P, Falup Pecurariu C, Odin P, van Hilten JJ, Antonini A, Rojo-Abuin JM, Borges V, Trenkwalder C, Aarsland D, Brooks DJ, Ray Chaudhuri K: Gender-related differences in the burden of non-motor symptoms in Parkinson's disease. J Neurol 2012;259: 1639-1647.

46 Politis M, Wu K, Molloy S, G Bain P, Chaudhuri KR, Piccini P: Parkinson's disease symptoms: the patient's perspective. Mov Disord 2010;25:1646-1651.

47 Ray Chaudhuri K, Rojo JM, Schapira $\mathrm{AH}$, Brooks DJ, Stocchi F, Odin P, Antonini A, Brown RG, Martinez-Martin P: A proposal for a comprehensive grading of Parkinson's disease severity combining motor and nonmotor assessments: meeting an unmet need. PLoS One 2013;8:e57221.

48 Zhang L, Yan J, Xu Y, Long L, Zhu C, Chen X Jiang Y, Yang L, Bian L, Wang Q: The combination of homocysteine and C-reactive protein predicts the outcomes of Chinese patients with Parkinson's disease and vascular parkinsonism. PLoS One 2011;6:e19333.

49 Tsuboi Y, Yamada T, Chaudhuri KR, Martinez-Martin P, Schapira AH; Group TiPNM: Comparison of profile of no motor symptoms in Japense patients with PD with European patients and healthy controls. Extension of the NMSQuest study. Mov Disord 2006;21:S648.

50 Maeda T, Shimo Y, Chiu SW, Yamaguchi T, Kashihara K, Tsuboi Y, Nomoto M, Hattori N, Watanabe H, Saiki H: Clinical manifestations of nonmotor symptoms in 1021 Japanese Parkinson's disease patients from 35 medical centers. Parkinsonism Relat Disord 2017;38:54-60.

51 Martinez-Martin P, Schapira AH, Stocchi F, Sethi K, Odin P, MacPhee G, Brown RG, Naidu Y, Clayton L, Abe K, Tsuboi Y, MacMahon D, Barone P, Rabey M, Bonuccelli U, Forbes A, Breen K, Tluk S, Olanow CW, Thomas S, Rye D, Hand A, Williams AJ, Ondo W, Chaudhuri KR: Prevalence of nonmotor symptoms in Parkinson's disease in an international setting; study using nonmotor symptoms questionnaire in 545 patients. Mov Disord 2007;22:1623-1629.

52 Das D, Biswas A, Roy A, Sauerbier A, Bhattacharyya KB: Cognitive impairment in idiopathic Parkinson's disease. Neurol India 2016;64:419-427.

53 Crispo JA, Willis AW, Thibault DP, Fortin Y, Hays HD, McNair DS, Bjerre LM, Kohen DE, Perez-Lloret S, Mattison DR, Krewski D: Associations between anticholinergic burden and adverse health outcomes in Parkinson disease. PLoS One 2016;11:e0150621.

54 Romenets SR, Wolfson C, Galatas C, Pelletier A, Altman R, Wadup L, Postuma RB: Validation of the non-motor symptoms questionnaire (NMS-Quest). Parkinsonism Relat Disord 2012;18:54-58. 
55 Li H, Zhang M, Chen L, Zhang J, Pei Z, Hu A, Wang Q: Nonmotor symptoms are independently associated with impaired health-related quality of life in Chinese patients with Parkinson's disease. Mov Disord 2010;25:27402746.

56 Prakash KM, Nadkarni NV, Lye WK, Yong $\mathrm{MH}$, Tan EK: The impact of non-motor symptoms on the quality of life of Parkinson's disease patients: a longitudinal study. Eur J Neurol 2016;23:854-860.

57 Barone P, Antonini A, Colosimo C, Marconi R, Morgante L, Avarello TP, Bottacchi E, Cannas A, Ceravolo G, Ceravolo R, Cicarelli G, Gaglio RM, Giglia RM, Iemolo F, Manfredi M, Meco G, Nicoletti A, Pederzoli M, Petrone A, Pisani A, Pontieri FE, Quatrale R, Ramat S, Scala R, Volpe G, Zappulla S, Bentivoglio AR, Stocchi F, Trianni G, Dotto PD: The PRIAMO study: a multicenter assessment of nonmotor symptoms and their impact on quality of life in Parkinson's disease. Mov Disord 2009;24:1641-1649.

58 Nataliya Titova PJ, Ray Chaudhuri K: The future of Parkinson's treatment - personalised and precision medicine. Eur Neurol Rev 2017; 12:15-16.

59 Zis P, Martinez-Martin P, Sauerbier A, Rizos A, Sharma JC, Worth PF, Sophia R, Silverdale M, Chaudhuri KR: Non-motor symptoms burden in treated and untreated early Parkinson's disease patients: argument for non-motor subtypes. Eur J Neurol 2015;22:11451150.

60 Jaquet M, Rochat I, Moulin J, Cavin C, Bibiloni R: Impact of coffee consumption on the gut microbiota: a human volunteer study. Int J Food Microbiol 2009;130:117121.

61 Azmin S, Khairul Anuar AM, Tan HJ, Nafisah WY, Raymond AA, Hanita O, Shah SA, Norlinah MI: Nonmotor symptoms in a malaysian Parkinson's disease population. Parkinsons Dis 2014;2014:472157.

62 Wild S, Roglic G, Green A, Sicree R, King H: Global prevalence of diabetes: estimates for the year 2000 and projections for 2030. Diabetes Care 2004;27:1047-1053.

63 Zhang H, Yin X, Ouyang Z, Chen J, Zhou S, Zhang C, Pan X, Wang S, Yang J, Feng Y, Yu P, Zhang Q: A prospective study of freezing of gait with early Parkinson disease in Chinese patients. Medicine (Baltimore) 2016; 95:e4056.

64 Congress EP, Lyons BP: Cultural differences in health beliefs: implications for social work practice in health care settings. Soc Work Health Care 1992;17:81-96.

65 Zhang ZX, Chen H, Chen SD, Shao M, Sun SG, Qu QM, Zhang BR, Liu YM, Xu Q, Wan X, Li L, Wen HB, Chen X, Chen HB, Liu ZG, Wang J, Wang G: Chinese culture permeation in the treatment of Parkinson disease: a crosssectional study in four regions of China. BMC Res Notes 2014;7:65.

66 Chen W, Xiao Q, Shao M, Feng T, Liu WG, Luo XG, Chen XC, Xie AM, Liu CF, Liu ZG,
Liu YM, Wang J, Chen SD: Prevalence of wearing-off and dyskinesia among the patients with Parkinson's disease on levodopa therapy: a multi-center registry survey in mainland China. Transl Neurodegener 2014;3:26.

67 Chin Med Asso Neurology: Movement disorder and Parkinson disease. Treatment guideline of Parkinson disease. Chin J Neurol 2006; 39:409-412.

68 Lim SY, Tan ZK, Ngam PI, Lor TL, Mohamed H, Schee JP, Tan AK, Goh JY, Ooi E, Soh PC: Impulsive-compulsive behaviors are common in Asian Parkinson's disease patients: assessment using the QUIP. Parkinsonism Relat Disord 2011;17:761-764.

69 Auyeung M, Tsoi TH, Tang WK, Cheung CM, Lee CN, Li R, Yeung E: Impulse control disorders in Chinese Parkinson's disease patients: the effect of ergot derived dopamine agonist. Parkinsonism Relat Disord 2011;17: 635-637.

70 Guo YJ, Liao YC, Lin CH, Chang MH: Initial medication in patients of newly diagnosed Parkinson's disease in Taiwan. PLoS One 2014;9:e107465.

71 Bhidayasiri R, Hattori N, Jeon B, Chen RS, Lee MK, Bajwa JA, Mok VC, Zhang B, Syamsudin T, Tan LC, Jamora RD, Pisarnpong A, Poewe $\mathrm{W}$ : Asian perspectives on the recognition and management of levodopa 'wearing-off' in Parkinson's disease. Expert Rev Neurother 2015;15:1285-1297.

72 Peeraully T, Tan EK: Genetic variants in sporadic Parkinson's disease: East vs West. Parkinsonism Relat Disord 2012;18(suppl 1): S63-S65.

73 Huang T, Shu Y, Cai YD: Genetic differences among ethnic groups. BMC Genomics 2015; 16:1093.

74 Aharon-Peretz J, Rosenbaum H, GershoniBaruch R: Mutations in the glucocerebrosidase gene and Parkinson's disease in Ashkenazi Jews. N Engl J Med 2004;351:19721977.

75 Tan EK, Tong J, Fook-Chong S, Yih Y, Wong MC, Pavanni R, Zhao Y: Glucocerebrosidase mutations and risk of Parkinson disease in Chinese patients. Arch Neurol 2007;64:10561058.

76 Wu YR, Chen CM, Chao CY, Ro LS, Lyu RK, Chang KH, Lee-Chen GJ: Glucocerebrosidase gene mutation is a risk factor for early onset of Parkinson disease among Taiwanese. J Neurol Neurosurg Psychiatry 2007;78:977979.

77 Ziegler SG, Eblan MJ, Gutti U, Hruska KS, Stubblefield BK, Goker-Alpan O, LaMarca ME, Sidransky E: Glucocerebrosidase mutations in Chinese subjects from Taiwan with sporadic Parkinson disease. Mol Genet Metab 2007;91:195-200

78 Sidransky E, Nalls MA, Aasly JO, AharonPeretz J, Annesi G, Barbosa ER, Bar-Shira A, Berg D, Bras J, Brice A, Chen CM, Clark LN, Condroyer C, De Marco EV, Dürr A, Eblan MJ, Fahn S, Farrer MJ, Fung HC, Gan-Or Z, Gasser T, Gershoni-Baruch R,
Giladi N, Griffith A, Gurevich T, Januario C, Kropp P, Lang AE, Lee-Chen GJ, Lesage S, Marder K, Mata IF, Mirelman A, Mitsui J, Mizuta I, Nicoletti G, Oliveira C, Ottman R, Orr-Urtreger A, Pereira LV, Quattrone A, Rogaeva E, Rolfs A, Rosenbaum H, Rozenberg R, Samii A, Samaddar T, Schulte C, Sharma M, Singleton A, Spitz M, Tan EK, Tayebi N, Toda T, Troiano AR, Tsuji S, Wittstock M, Wolfsberg TG, Wu YR, Zabetian CP, Zhao Y, Ziegler SG: Multicenter analysis of glucocerebrosidase mutations in Parkinson's disease. N Engl J Med 2009;361: 1651-1661.

79 Huang CL, Wu-Chou YH, Lai SC, Chang HC, Yeh TH, Weng YH, Chen RS, Huang YZ, Lu $\mathrm{CS}$ : Contribution of glucocerebrosidase mutation in a large cohort of sporadic Parkinson's disease in Taiwan. Eur J Neurol 2011;18: 1227-1232.

$80 \mathrm{Hu}$ FY, Xi J, Guo J, Yu LH, Liu L, He XH, Liu $\mathrm{ZL}$, Zou XY, Xu YM: Association of the glucocerebrosidase N370S allele with Parkinson's disease in two separate Chinese Han populations of mainland China. Eur J Neurol 2010;17:1476-1478.

81 Mao XY, Burgunder JM, Zhang ZJ, An XK, Zhang JH, Yang Y, Li T, Wang YC, Chang XL, Peng R: Association between GBA L444P mutation and sporadic Parkinson's disease from Mainland China. Neurosci Lett 2010;469. 256-259.

82 Wang Y, Liu L, Xiong J, Zhang X, Chen Z, Yu L, Chen C, Huang J, Zhang Z, Mohmed AA, Lin Z, Xiong N, Wang T: Glucocerebrosidase L444P mutation confers genetic risk for Parkinson's disease in central China. Behav Brain Funct 2012;8:57.

83 Zhang X, Bao QQ, Zhuang XS, Gan SR, Zhao D, Liu Y, Hu Q, Chen Y, Zhu F, Wang L, Wang N: Association of common variants in the glucocerebrosidase gene with high susceptibility to Parkinson's disease among Chinese. Chin J Physiol 2012;55: 398-404.

84 Chen J, Li W, Zhang T, Wang YJ, Jiang XJ, Xu ZQ: Glucocerebrosidase gene mutations associated with Parkinson's disease: a meta-analysis in a Chinese population. PLoS One 2014; 9:e115747.

85 Wang C, Cai Y, Gu Z, Ma J, Zheng Z, Tang BS, $\mathrm{Xu}$ Y, Zhou Y, Feng T, Wang T, Chen SD, Chan P: Clinical profiles of Parkinson's disease associated with common leucine-rich repeat kinase 2 and glucocerebrosidase genetic variants in Chinese individuals. Neurobiol Aging 2014;35:725.e721-e726.

86 Brockmann K, Srulijes K, Pflederer S, Hauser AK, Schulte C, Maetzler W, Gasser T, Berg D: GBA-associated Parkinson's disease: reduced survival and more rapid progression in a prospective longitudinal study. Mov Disord 2015;30:407-411.

87 Pal G, Robertson E, O'Keefe J, Hall D: The neuropsychiatric and motor profile of GBAassociated Parkinson's disease: a review. Mov Disord Clin Pract 2016;3:4-8. 
88 Weinshilboum RM, Raymond FA: Inheritance of low erythrocyte catechol-o-methyltransferase activity in man. Am J Hum Genet 1977;29:125-135.

89 Jeanjean AP, Laterre EC, Maloteaux JM: Neuroleptic binding to sigma receptors: possible involvement in neuroleptic-induced acute dystonia. Biol Psychiatry 1997;41: 1010-1019.

90 Boudikova B, Szumlanski C, Maidak B, Weinshilboum R: Human liver catechol-O-methyltransferase pharmacogenetics. Clin Pharmacol Ther 1990;48:381-389.

91 McLeod HL, Syvanen AC, Githang'a J, Indalo A, Ismail D, Dewar K, Ulmanen I, Sludden J: Ethnic differences in catechol O-methyltransferase pharmacogenetics: frequency of the codon 108/158 low activity allele is lower in Kenyan than Caucasian or South-west Asian individuals. Pharmacogenetics 1998;8: 195-199.

92 Klemetsdal B, Straume B, Giverhaug T, Aarbakke J: Low catechol-O-methyltransferase activity in a Saami population. Eur J Clin Pharmacol 1994;46:231-235.
93 Kunugi H, Vallada HP, Sham PC, Hoda F, Arranz MJ, Li T, Nanko S, Murray RM, McGuffin P, Owen M, Gill M, Collier DA: CatecholO-methyltransferase polymorphisms and schizophrenia: a transmission disequilibrium study in multiply affected families. Psychiatr Genet 1997;7:97-101.

94 Makoff AJ, Graham JM, Arranz MJ, Forsyth J, Li T, Aitchison KJ, Shaikh S, Grunewald RA: Association study of dopamine receptor gene polymorphisms with drug-induced hallucinations in patients with idiopathic Parkinson's disease. Pharmacogenetics 2000;10:43-48.

$95 \mathrm{Kim} \mathrm{HJ}$, Jeon B: How close are we to individualized medicine for Parkinson's disease? Expert Rev Neurother 2016;16:815-830.

96 Pocock SJ, Elbourne DR: Randomized trials or observational tribulations? N Engl J Med 2000;342:1907-1909.

97 Sauerbier A, Lenka A, Aries A, Pal PK: Nonmotor symptoms in Parkinson's disease: gender and ethnic differences. Int Rev Neurobiol 2017 (submitted).
98 SauerbierA, Klingelhoefer L, Banerjee R, Diaconu S, Erro R, Farombi T, Gangadharan S, Macerollo A, Chahine L, Jitkritsadakul O, Biundo R, Grilo M, Dafsari H, Pagano G, Niccolini F, Titova N: A global survey of the use and linguistic translation of the NMSQuest and NMSScale: implications for non-motor studies in Parkinson's disease. Mov Disord 2017;32(suppl 2). http://www.mdsabstracts.org/abstract/ a-global-survey-of-the-use-and-linguistictranslation-of-the-nmsquest-and-nmsscaleimplications-for-non-motor-studies-inparkinsons-disease/ (accessed June 29, 2017).

99 Ohayon MM, O'Hara R, Vitiello MV: Epidemiology of restless legs syndrome: a synthesis of the literature. Sleep Med Rev 2012;16: 283-295.

100 Yu RL, Wu RM, Chan AY, Mok V, Wu YR Tilley BC, Luo S, Wang L, LaPelle NR, Stebbins GT, Goetz CG: Cross-cultural differences of the non-motor symptoms studied by the traditional Chinese version of the International Parkinson and Movement Disorder Society - Unified Parkinson's Disease Rating Scale. Mov Disord Clin Pract 2017;4:68-77. 